NOTICE: this is the author's version of a work that was accepted for publication in Computers in Human Behavior. Changes resulting from the publishing process, such as peer review, editing, corrections, structural formatting, and other quality control mechanisms may not be reflected in this document. Changes may have been made to this work since it was submitted for publication. A definitive version was subsequently published in Computers in Human Behavior, VOL 39, (2014). DOI: 10.1016/j.chb.2014.07.004

\title{
Publically different, privately the same: Gender differences and similarities in response to Facebook status updates
}

\author{
Richard Joiner \\ Department of Psychology, University of Bath, Bath, UK. \\ r.joiner@bath.ac.uk \\ Caroline Stewart \\ School of Management, University of Bath, Bath, UK. \\ c.stewart@bath.ac.uk \\ Chelsey Beaney \\ School of Management, University of Bath, Bath, UK. \\ c.beaney@bath.ac.uk
}

Amy Moon

Department of Psychology and Counseling, University of Greenwich, London, UK a.moon@greenwich@bath.ac.uk

Pam Maras

Department of Psychology and Counseling, University of Greenwich, London, UK

p.f.maras@greenwich.ac.uk

Jane Guiller

Department of Psychology, Glasgow Caledonian University, Glasgow, UK

j.guiller@gcu.ac.uk

\section{Helen Gregory}

Department of Psychology, University of Gloucestershire, Gloucester, UK

h.gregory@glos.ac.uk

Jeff Gavin 
Department of Psychology, University of Bath, Bath, UK.

\title{
John Cromby
}

Psychology Division, University of Loughborough, Loughborough, UK

j.cromby@lboro@bath.ac.uk

\section{Mark Brosnan}

Department of Psychology, University of Bath, Bath, UK.

m.j.brosnan@bath.ac.uk

\section{Publically different, privately the same: Gender differences and similarities in response to Facebook status updates}

\begin{abstract}
Social networking sites (SNS), and especially Facebook, have revolutionised patterns of language and communication. We conducted a study to examine gender differences in language use on Facebook, by surveying 600 undergraduate students (388 females and 207 males), and analysing males' and females’ responses to two Facebook status updates. There were a number of gender differences in terms of public replies to Facebook status updates. Females were significantly more likely to 'like' a Facebook status update than males, post a public reply to a Facebook status update than males and show higher levels of emotional support than males. In contrast there were hardly any gender differences in terms of sending private messages in response to Facebook status updates. There was no gender difference in terms of level of emotional support in private messages. Females were more likely to send a private message than males, but this difference was very small. The implications of these findings for explanations of gender differences in language are discussed.
\end{abstract}


Keywords: Social Networking Sites, Facebook, Gender, Language, Context 


\section{Introduction}

Social networking sites (SNSs) are becoming an integral part of everyday life, with more than a billion monthly active users on Facebook alone (Facebook Newsroom, 2014), and 66\% of online adults using a SNS (Hampton, Sesions Goulet, Rainie, and Purcell 2011). However, recent research demonstrates that males and female use these sites differently.

Large scale surveys have found more females than males use SNS. Hampton et al. (2011), for example, reported that 56\% of SNS users were female, and Madden and Zickhur (2011), who reported females were not only more likely to use SNS, but were more likely to be daily visitors then males. Furthermore, a number of studies have found that females spend more time on SNSs than males. Denti et al, (2012), reported that on average, females spend 84 minutes a day on Facebook, compared to 64 minutes for males, with similar figures obtained by Shambare and Mvula (2011), and Moore and McElroy (2011). Additionally, further studies have shown there are also gender differences in SNS use and activities, with females tending to use SNS for communicating and connecting with others, and males for gathering information (Denti et al., 2012; Junco, 2013; Smith, 2011).

\subsection{Gender differences in language}

Although the work above has shown that females are more likely to be prolific SNS users, there is little research into gender differences in language on SNS, despite these sites being (for many), an extremely important method of communication. In contrast, research on gender differences in written and spoken language and communication is a major area of research (Lakoff, 1975; Tannen, 1990). One of the most consistent findings (and one with obvious parallels to differences in SNS use) is that females are more likely to use affiliative language (used for connecting to others), whereas males are more likely to use self-assertive 
language (used for dominance, and achieving practical goals). For a recent review see Leaper (2014).

There are two main explanations for these gender differences in language. The first is the socialisation theory (Matz and Borker, 1982), which emphasises the impact of gender stereotypical activities, and same sex peer groups. By participating in these gender segregated peer groups and their associated activities, males and females develop different norms, social identities and language use. For example, research has shown that girls’ interactions are more likely to involve cooperative social dramatic activities, and boys are more likely to participate in more solitary or competitive group play (see Maccoby, 1998). Matz and Borker (1982), argue that these gender differences in activities lead to gender differences in language. Girls learn to use language to create and maintain social closeness through supportive and inclusive forms of talk, and boys use language to assert their dominance through commands and challenging statements. This theory predicts that gender differences in language will be greatest in same gender interactions, as partners of the game gender would share similar social norms concerning language and communication (Carli, 1989, 1990).

The second explanation is the social context theory (Deaux and Major, 1987; Eagly, Wood and Diekman, 2000; Leaper, 2000), which emphasises the social interactive impact of context, rather than individual factors. As contextual factors change, so to would males' and females' language and communication. For example, one important aspect of contextual influence is males' greater status in society. Males may therefore be more likely to dominate social interactions through the use of self-assertive language, whereas women may be more likely to act subordinately through using more affiliative language. Another important aspect of contextual influence is the activity setting. Males and females often engage in different activities, which in turn have their associated patterns of language. Affiliative language is more appropriate in self-disclosure tasks (more commonly associated with females), and 
assertive language is more appropriate in task oriented activities (more commonly associated with males). Finally, another important aspect of context is group size and familiarity. Deaux and Major (1987) showed that people behave in more stereotypical ways in front of larger and unfamiliar groups. Thus, females are more likely to use affiliative language than males in a large group context in front of unfamiliar people, whereas in private communication in a 1 to 1 communication context with a familiar person these gender differences in affiliative language will be reduced. Thus, the social context drives the language males and females use, and therefore gender differences can be expected to fluctuate across situations. These two explanations are not mutually exclusive and could both explain any observed gender differences in language use.

Recent empirical support for gender differences in language. has been summarized in a meta-analysis by Leaper and Ayres (2007) , who compared males and females both on talkativeness, and their use of assertive and affiliative language. Males were found to be more talkative than females, and used significantly more assertive language, whereas females used significantly more affiliative language. A recent study on language use in multiplayer video games found a similar pattern of results. Kuznekoff and Rose (2013) investigated gamers’ reactions to male voices compared to their reactions to female voices. They found that the female voice received three times as many negative comments as the male voice or no voice. Furthermore, the female voice received more queries and more messages from other gamers than the male voice.

As mentioned above, there has been considerable research on gender difference in language use in general, but there have been very few studies that have explored gender differences in language use on social media. One exception is Thelwell, Wilkinson and Uppal (2009), who explored gender differences in emotional language in MySpace comments. They found similar gender differences to Leaper and Ayres (2007), with females using more affiliative 
language. Female comments contained more instances of positive emotion and support than males, yet there was no difference in terms of negative emotion. Another more recent study by Wang Burke \& Kraut (2013) investigated gender differences in the topic and the audience response of Facebook status updates. They found that females tended to share more personal topics, while males discussed more public topics. Females received more feedback, although topics posted by males received more feedback, especially by females. Finally, Walton \& Rice (2013) analysed 3751 tweets and found that females were more positive, disclosed more information and disclosed more private information than males. They argued this finding was reflecting females’ societal gender role as more nurturing and emotional.

The aim of the current study is to extend this research, and examine gender differences in language use on Facebook (especially the differences in affiliative language), by analysing public and private replies to different Facebook status updates. Public replies to Facebook status updates could be viewed as communication in a larger group context, whereas private messages could be viewed as communication in a small group or one to one context with a familiar person. The socialisation perspective, would predict that gender differences in affiliative language would be evident regardless of whether it is a public reply or private message in response to a Facebook status update. Therefore, the study will test the following two hypotheses.

H1: Females will use more affiliative language than males when replying publically to a Facebook status update than males.

H2: Females will use more affiliative language than males when sending a private message to a Facebook status update than males.

In contrast, the social context perspective would predict that gender differences would be more evident in public replies and would be less evident and may even disappear with private messages. 


\section{Method}

\subsection{Participants}

The participants were 600 first year undergraduate students (388 females and 207 males), with a mean age of $19.2(\mathrm{SD}=2.76)$.

\subsection{Procedure and Measures}

The questionnaire was distributed during lectures and contained two Facebook status updates: 'I’m having a really rubbish day’ and ‘Oooooh my iPhone has arrived! Will pick it up tomorrow v v v exciting'. Both Facebook status updates were selected as examples of selfdisclosure: one positive and one negative and could be classified as personal Facebook status updates using the classification scheme developed by Winter et al., (2014), who found that they were the most common Facebook status updates. Also, they are topics which are more likely to be posted by Females than Males (Wang et al., 2013). In the questionnaire, the participants were asked would they 'Like' the Facebook status update ("Yes” or "No”), write a public reply to the Facebook status update ("Yes” or "No"), and/or send the close friend a private message ("Yes” or "No"). If they indicated they would write a public reply or a private message, they were asked what they would write.

\subsection{Analysis}

We measured the level of emotional support expressed in the public replies and personal messages by adapting the classification system developed by Thelwall et al. (2009), shown in table 1. 
Table 1.

Coding System for Levels of Support in Facebook Status Responses.

Level Label $\quad$ Examples

' 0 ' Absence of any supportive elements 'My day is probably worse than yours'

'1' Some weak supportive elements 'What's wrong?'

'2' Clear supportive elements 'What's wrong babe? :(‘

'3' Multiple supportive elements 'Hey, what's wrong? Give me a call xxx'

‘4’ Overwhelmingly supportive elements

'Ah what's up? Are you ok? Do you want to talk? Big hugs? Xx’

Two raters coded the responses, however the comments to the 'iPhone' status were not analysed due to the extremely low response rate. For public messages, the level of agreement between the two raters was kappa $=0.84$, and for private messages kappa $=0.77$, which is high (Landis and Koch, 1977).

\section{Results}

\subsection{Public Replies to a Facebook status update}

There were a number of gender differences in terms of public replies to Facebook status updates. In response to the 'Rubbish Day' Facebook status update, there was a significant gender difference in terms of whether an individual would write a public reply to this 
Facebook status update, $\chi^{2} 2(1, \mathrm{~N}=587)=20.35, \mathrm{p}<0.005, \phi=0.19$. Females $(36.9 \%)$ were nearly twice more likely to post a public reply than males (18.8\%). Furthermore there was a significant gender difference (as shown in Table 2), in the level of emotional support in public replies $(\mathrm{t}(57)=-3.43, \mathrm{p}<0.005, \mathrm{~d}=0.70)$. Females $(\mathrm{M}=1.54, \mathrm{SD}=0.85)$ showed higher levels of support than males $(\mathrm{M}=0.98, \mathrm{SD}=0.75)$. There was no gender difference in terms of whether participants would 'Like' the 'Rubbish Day' Facebook status update $\left(\chi^{2}\right.$ $(1, N=579)=0.05, p=.83, \phi=0.01)$. Males $(12.5 \%)$ were as likely to say they would 'Like' the ‘Rubbish Day’ Facebook status update as females (11.9\%).

Table 2.

Male and Female Facebook Status Replies to 'Rubbish Day' Status Update.

\begin{tabular}{|c|c|c|c|c|}
\hline \multirow[b]{2}{*}{ Code } & \multicolumn{2}{|c|}{ Male } & \multicolumn{2}{|c|}{ Female } \\
\hline & $\mathrm{N}$ & $\%$ & $\mathrm{~N}$ & $\%$ \\
\hline Absence of any supportive elements & 11 & 32.4 & 10 & 7.6 \\
\hline Some weak supportive elements & 17 & 50.0 & 65 & 49.2 \\
\hline Clear supportive elements & 6 & 17.6 & 38 & 28.8 \\
\hline Multiple supportive elements & 0 & 0.0 & 17 & 12.9 \\
\hline Overwhelmingly supportive elements & 0 & 0.0 & 2 & 1.5 \\
\hline
\end{tabular}

Similar findings were found in response to the iPhone Facebook status update. Nearly twice as many females (63.5\%) said they would 'Like' the 'iPhone’ Facebook status update 
compared to only 35.2\% of males $\left.\chi^{2}(1, \mathrm{~N}=584)=42.71, \mathrm{p}<0.005 .00, \phi=0.27\right)$.

Furthermore, Table 3 shows there was a significant gender difference in terms of the level of emotional support in public replies $(t(61)=3.20, p<0.005, d=0.85)$, with females $(M=$ $0.79, \mathrm{SD}=0.63)$ showing higher levels of support than males $(\mathrm{M}=0.32, \mathrm{SD}=0.48)$. There was no significant gender difference in terms of whether an individual would write a public reply to the Facebook status update, $\chi^{2}(1, \mathrm{~N}=573)<1, \mathrm{p}=.40, \phi=0.04$, with females (10.2\%) as likely to post a public reply as males (12.5\%).

Table 3.

Male and Female Facebook Private Message Responses to 'Rubbish Day’ Status Update.

\begin{tabular}{|c|c|c|c|c|}
\hline \multirow[b]{2}{*}{ Code } & \multicolumn{2}{|c|}{ Male } & \multicolumn{2}{|c|}{ Female } \\
\hline & $\mathrm{N}$ & $\%$ & $\mathrm{~N}$ & $\%$ \\
\hline Absence of any supportive elements & 0 & 0.0 & 0 & 0.0 \\
\hline Some weak supportive elements & 51 & 67.1 & 106 & 58.2 \\
\hline Clear supportive elements & 18 & 23.7 & 52 & 28.6 \\
\hline Multiple supportive elements & 5 & 6.6 & 18 & 9.9 \\
\hline Overwhelmingly supportive elements & 2 & 2.6 & 6 & 3.3 \\
\hline
\end{tabular}

\subsection{Private messages to a Facebook status update}

Unlike the public replies to Facebook status updates, there were very few gender differences observed in terms of sending private messages to Facebook status updates. Furthermore the 
gender differences that were observed were very small. In terms of the 'Rubbish Day’ Facebook status update Females (54.3\%) were significantly more likely to send a private message than males (44.7\%), $\chi^{2}(1, \mathrm{~N}=578)=4.85, \mathrm{p}=0.03, \phi=0.09$, but the effect size was very small. There was no significant difference between males $(\mathrm{M}=1.45, \mathrm{SD}=0.74)$ and females $(\mathrm{M}=1.56, \mathrm{SD}=0.80)$ in terms of emotional support shown in private messages, $\mathrm{t}(256)=-1.26, \mathrm{p}=0.20, \mathrm{~d}=0.14$ (see Table 4).

Table 4.

Male and Female Facebook Status Replies to 'IPhone’ Status Update.

\begin{tabular}{|c|c|c|c|c|}
\hline \multirow[b]{2}{*}{ Code } & \multicolumn{2}{|c|}{ Male } & \multicolumn{2}{|c|}{ Female } \\
\hline & $\mathrm{N}$ & $\%$ & $\mathrm{~N}$ & $\%$ \\
\hline Absence of any supportive elements & 17 & $68 \%$ & 12 & 31.6 \\
\hline Some weak supportive elements & 8 & $32 \%$ & 22 & 57.9 \\
\hline Clear supportive elements & 0 & 0 & 4 & 10.5 \\
\hline Multiple supportive elements & 0 & 0 & 0 & 0 \\
\hline Overwhelmingly supportive elements & 0 & 0 & 0 & 0 \\
\hline
\end{tabular}

Similar findings were found for private messages in response to the 'iPhone' Facebook status update. There was no significant gender difference in terms of whether they would send a 
private message, $\chi^{2}(1, \mathrm{~N}=570)<1, \mathrm{p}=.41, \phi=0.03$. Only $2.4 \%$ of females and $3.6 \%$ of males said they would respond to the 'iPhone’ Facebook status update with a personal message. Moreover, there was no gender difference in terms of level of emotional support provided in private messages $(\mathrm{t}(12)=0.4, \mathrm{p}=0.4, \mathrm{~d}=0.46)$, although it has to be noted that the numbers are very small (see table 5).

Table 5.

Male and Female Facebook Private Message Responses to 'IPhone’ Status Update.

\begin{tabular}{|c|c|c|c|c|}
\hline \multirow[b]{2}{*}{ Code } & \multicolumn{2}{|c|}{ Male } & \multicolumn{2}{|c|}{ Female } \\
\hline & $\mathrm{N}$ & $\%$ & $\mathrm{~N}$ & $\%$ \\
\hline Absence of any supportive elements & 4 & $66.7 \%$ & 4 & 50.0 \\
\hline Some weak supportive elements & 2 & $33.3 \%$ & 3 & 37.5 \\
\hline Clear supportive elements & 0 & 0.0 & 1 & 12.5 \\
\hline Multiple supportive elements & 0 & 0.0 & 0 & 0.0 \\
\hline Overwhelmingly supportive elements & 0 & 0.0 & 0 & 0.0 \\
\hline
\end{tabular}

\section{Discussion}

The aim of this study was to investigate gender differences in public and private affiliative language in response to two Facebook status updates. There were a number of significant gender differences in terms of public replies to Facebook status updates. Females were 
significantly more likely to 'Like' the iPhone Facebook status update and they were significantly more likely to reply publically to the 'Rubbish Day’ Facebook status update. Furthermore, females showed significantly higher levels of emotional support in their public replies than males, for both Facebook status updates. In contrast, this gender difference virtually disappeared when it came to private messages. There was no significant difference between males and females in terms of the level of emotional support in private messages for both status updates. Moreover, there was no significant difference between males and females in terms of the number of private messages sent for the 'Rubbish Day' Facebook status update and there was only a small significant difference between males and females in terms of the number of private messages sent for the 'iPhone' Facebook status update. Females were more likely to send a private message than males.

These findings provide support for the social context perspective rather than the socialisation perspective of gender differences in language use. Both explanations would predict that females would use more affiliative language than males in public replies. The key difference lies with the private responses to Facebook status updates. The socialisation explanation would expect the gender difference to remain in private responses to Facebook status updates. In contrast, the social context explanation would predict that the gender difference will be much less for private messages. Research from a social context perspective has shown that people are more likely to behave in stereotypical ways in front of larger groups and groups they are unfamiliar with (Deaux and Major, 1987, Leman 2010) than inf rom of small groups of people they are familiar with. Public replies to Facebook status updates can be viewed as communication in a large group context in front of unfamiliar people, whereas private messages can be viewed as one to one communications with a familiar person. Both status updates are examples of self-disclosure (a stereotypically female topic), which may be why females appeared to be more comfortable publically responding to 
these Facebook status update than males, whereas in private individuals behave in less stereotypical ways and thus the gender differences observed were reduced.

In the current research, we asked the participants how they would respond to a Facebook status update from a close friend, but did not specify whether it was a friend of the same or opposite gender. Interestingly, the different theories behind gender differences in language would make conflicting predictions about language in relation to a same or opposite gender friend (Carli, 1989, 1990). The socialisation explanation would predict that the most substantial gendered language differences would come from same-gendered friend, as both parties would be following the same behavioural norms. On the other hand, the social context explanation would predict that gender differences would be most obvious when respondents replied to an opposite gender friend, as the differences in behavioural norms would be more salient (Carli, 1989, 1990).

Research concerning gender differences in language has found more support for the socialisation explanation. Males are more talkative in general than females in mixed gender interactions (Leaper and Ayres, 2007), and females use more affiliative language in same gender interactions than males, and males use more assertive language in same gender interactions, yet these differences disappear in mixed gender interactions (Leaper and Ayres, 2007). It would be interesting to conduct further research to explore whether the gender differences we observed in this study would depend on whether participants were responding to a friend of the same or opposite gender. Interestingly, one male participant in the current study provided alternative responses for the 'Rubbish Day’ Facebook status update depending on whether it was a friend of the same or different gender. His response to a male was 'What's up you wet wipe', whereas for a female it was 'what's up sweetie x', which again supports the social context argument. 
One limitation with this study was that we used paper and pencil questionnaires rather than observing naturalistically responses to Facebook status updates. A naturalistic study would be interesting to investigate whether similar results would be found. Other studies have reported that Females are more likely to respond to Facebook status updates which are about personal issues (Wang et al., 2013). Unfortunately, a naturalistic study would have difficulty observing participants private messages because of privacy and ethical reasons and it was the findings concerning participants private messages which were the most theoretically interesting and came up with the most interesting results. However, future research could explore these findings using a more naturalistic methodology.

In conclusion, in this study we found that females were more likely than males to show affiliative and supportive language in public replies to a Facebook status update, but that this gender difference in language disappeared with private messages. These findings provide support for the social context explanation for gender differences in language and shows that gender has an important role to play in the language used on social networking sites.

\section{References}

Carli, L. L. (1989). Gender differences in interaction style and influence. Journal of Personality \& Social Psychology, 56, 565-576.

Carli, L. L. (1990). Gender, language, and influence. Journal of Personality \& Social Psychology, 59, 941-951.

Deaux, K., \& Major, B. (1987). Putting gender into context: An interactive model of genderrelated behavior. Psychological Review, 94, 369-389.

Denti, L., Barbopuolos, I., Nilsson, I., Holmberg, L., Thulin, M., Wendeblad, M. \& Davidsson, E. (2012). Sweden's largest Facebook study. Gothenburg Research Institute. Retrieved July $30^{\text {th }}$, 2013 from http://gri.gu.se/english/latest- 
news/news/d//sweden-s-largest-facebook-study--a-survey-of-1000-swedish-facebook$\underline{\text { users.cid1073014 }}$

Eagly, A. H., Wood, W., \& Diekman, A. B. (2000). Social role theory of sex differences and similarities: A current appraisal. In T. Eckes \& H. M. Trautner (Eds.), The developmental social psychology of gender (pp. 123-174). Mahwah, NJ: Lawrence Erlbaum.

Key Facts, Facebook Newsroom (2014). Retrieved May 28 ${ }^{\mathrm{h}}, 2014$ from http://newsroom.fb.com/Key-Facts

Kuznekoff, J. H., \& Rose, L. M. (2013). Communication in multiplayer gaming: examining player responses to gender cues. New Media \& Society, 15(4), 541-556

Hampton, K. N., Sesions Goulet, L., Rainie, L., \& Purcell, K. (2011). Social networking sites and our lives. Pew Internet and American Life Project. Retrieved July 30 ${ }^{\text {th }}, 2013$ from http://www.pewinternet.org/Reports/2011/Technology-and-social-networks.aspx

Junco, R. (2013). Inequalities in Facebook use. Computers in Human Behavior, 29, 23282336

Lakoff, R. (1975). Language and woman’s place. New York: Harper \& Row.

Landis, J. R., \& Koch, G. G. (1977). The measurement of observer agreement for categorical data. Biometrics, 33(1), 159-174.

Leaper, C. (2000). The social construction and socialization of gender. In P. H. Miller \& E. K. Scholnick (Eds.), Toward a feminist developmental psychology (pp. 127-152). New York: Routledge.

Leaper, C. (2014). Gender similarities and differences in language use. In T. Holtgraves (Ed.), Oxford handbook of language and social psychology. Oxford University Press. 
Leaper, C., \& Ayres, M.M. (2007). A meta-analytic review of gender variations in adults’ language use: Talkativeness, affiliative speech, and assertive speech. Personality and Social Psychology Review, 11(4), 328-363.

Leman, P. J. (2010). Gender, Collaboration, and Children’s Learning. In K. Littleton \& C. Howe (Eds.), Educational Dialogues: Understanding and Promoting Effective Interaction (pp. 216-239). Oxford, UK: Taylor and Francis.

Maccoby, E. E. (1998). The two sexes: Growing up apart, coming together. Cambridge, MA: Harvard University Press.

Madden, M., \& Zickuhr, K. (2011). 65\% of online adults use social networking sites. Pew Research Center.

Maltz, D. N., \& Borker, R. A. (1982). A cultural approach to male female miscommunication. In J. J. Gumperz (Ed.), Language and social identity (pp. 196-216). Cambridge, UK: Cambridge University.

Moore, K., \& McElroy, J. C. (2011). The influence of personality on Facebook usage, wall postings, and regret. Computers in Human Behavior,28(1), 267-274.

Shambare, R., \& Mvula, A. (2011). South African students’ perceptions of Facebook: Some implications for instructors. African Journal of Business Management, 5(26), 1056710564.

Smith, A. (2011). Why Americans use social media. Pew Internet and American Life Project. Retrieved July 30" 2013 from http://www.pewinternet.org/Reports/2011/WhyAmericans-Use-Social-Media/Main-report.aspx

Tannen, D. (1990). You just don't understand: Men and women in conversation. New York: Ballantine. 
Thelwall, M., Wilkinson, D., \& Uppal, S. (2009). Data mining emotion in social network communication: Gender differences in MySpace. Journal of the American Society for Information Science and Technology, 61(1), 190-199.

Walton, S. C. \& Rice, R. E. (2013). Mediated disclosure on twitter: The roles of gender and identity in boundary impermeability, valence, disclosure, and stage. Computers in Human Behavior, 29(4), 1466-1474

Wang, Y. C., Burke, M., \& Kraut, R. E. (2013). Gender, topic, and audience response: an analysis of user-generated content on Facebook. In Proceedings of the SIGCHI Conference on Human Factors in Computing Systems (pp. 31-34). New York: ACM.

Winter, S., Neubaum, G., Eimler, S. C., Gordon, V., Theil, J. Herrmann, J., Meinert, J., \& Krämer, N. C. (2014). Another brick in the Facebook wall - How personality traits relate to the content of status updates. Computers in Human Behavior, 34, 194-202 